\title{
Effectiveness of an 'Instructional Teaching Programme' (ITP) on the Knowledge of Postnatal Mothers regarding Newborn Care
}

\author{
Ms. Kanchan Bala ${ }^{1}$, Mrs. RajKumari Sylvia Devi ${ }^{2,}$ Mrs. Gomathi B. ${ }^{3}$ \\ ${ }^{1,3}$ (Obstetrics and Gynecology, Himalayan College of Nursing, Dehradun, India) \\ ${ }^{2}$ (Child health Nursing, Himalayan College of Nursing, Dehradun, India)
}

\begin{abstract}
The challenge of newborn health faced by India is more than any other country in the world. Globally out of 3.9 million, 30\% neonatal deaths occur in India. A Quasi-experimental study was undertaken to assess the effectiveness of an 'Instructional Teaching Programme' (ITP) on the Knowledge of Postnatal Mothers regarding Newborn Care in multi-specialty, teaching hospital in Uttarakhand. Total 62 postnatal mothers were selected by consecutive sampling technique. The pre-test was taken by using structured knowledge questionnaire designed by researcher and validated by the various experts in the specific field followed by Instructional Teaching Programme. After 7 days post-test was taken. The overall mean pre-test knowledge

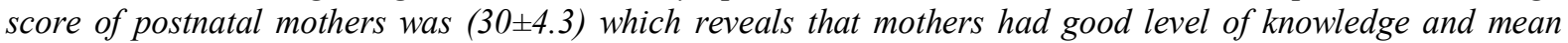
post-test knowledge score of postnatal mothers was $(42 \pm 1.1)$ which revealed that mothers had very good level of knowledge and ' $t$ ' value for total pretest and posttest was 22.22. Area wise post-test highest mean percentage was (96\%) in the area of breast feeding and the lowest mean percentage was $(88.88 \%)$ in the area of prevention of low body temperature. No significant association was found between pretest knowledge scores with their demographic variables except age. The findings of the study concluded that 'Instructional Teaching Programme' (ITP) was effective to increase the knowledge of postnatal mothers regarding newborn care.

Keywords- Instructional Teaching Programme, Knowledge, Newborn Care, Postnatal Mothers
\end{abstract}

\section{INTRODUCTION}

A healthy population is the nation's prosperity. Healthy children today, make a healthier nation tomorrow. The role of the mother in creating a healthy nation is eminent and beyond explanation. ${ }^{1}$ Among the life span of the childhood period. The neonatal period is very crucial to large extent determines the overall health status of the child and in turn adult life. Birth is a major challenge to the newborn to negotiate successfully from intrauterine to extrauterine life. The newborn baby is considered to be tiny and powerless, completely dependent on others for life. ${ }^{2}$

Neonates are 'at risk' for various health problems, even though they are born with average birth weights. The morbidity and mortality rates in newborn infants are high. They need optimal care for improved survival. Neonatal care is highly cost-effective because saving the life of a newborn baby is associated with survival and productivity of the future adult. Although parents are ultimately responsible for this care, nurses usually assume a major care-giving role while the infant is in the nursery., ${ }^{3,4}$

Good hygiene by nurses, mothers would reduce the likelihood of cold, dermatitis, herpes, and skin diseases being spread to more sensitive individuals in the family. Newborn babies are also at risk from maternal infection if hygiene is not adequate. The daily cleansing of the infant affords an excellent opportunity for making the observation that necessary during the immediate postnatal period. ${ }^{5}$

The health challenge of the newborn that India faces is more formidable than experienced by any other country in the world. It is estimated that out of 3.9 million neonatal deaths that occur worldwide, almost $30 \%$ occur in India. Globally, under five years of age, mortality rates have declined over the past four decades, but the neonatal mortality rates still remain high. ${ }^{1}$ Although the neonatal mortality rate (NMR) shows a decreasing trend, compared to $25 \%$ reduction in the neonatal deaths in 1980 's, the decline in 1990 's was only $15 \%{ }^{2}$

\subsection{Need of Study:}

The healthy newborn infant born at term, between 38 to 42 weeks, cries immediately after birth, establishes independent rhythmic respiration, quickly adapts with the extra-uterine environment, has an average birth weight and no congenital anomalies.

According to WHO report, the global birth rate is 27.3 per 1,000 populations. In Nepal crude birth rate is 34 per 1000 and 13 death occurs in 100 live births. Two third of all deaths in first year occurs in the neonatal period. In India it is reported that $50-60 \%$ of all neonatal deaths occur within the first month of life. Of these, more than half may die during the first week of life. Most of the deaths are due to birth asphyxia, hypothermia and infections which are preventable if the quality of care is maintained. ${ }^{6}$ Worldwide; about eight newborn 
babies die every minute. Every year more than four million babies die during first week of life due to inadequate care by mothers/ caregivers. ${ }^{6}$

India accounts for $27 \%$ of global neonatal deaths and $30 \%$ of neonatal mortality in the state of Uttar Pradesh (UP). Thus, nearly 10\% of all global neonatal deaths take place in this state of India. The characteristics of this part of India are very similar to several other Indian states as well as large sections of Bangladesh, Southern Nepal and Pakistan.

Irrespective of urban-rural differences in NMR, neonatal deaths are a bane of the poor. The major causes of neonatal deaths globally are estimated to be complications of prematurity (28\%), sepsis and pneumonia (26\%), birth asphyxia and injuries $(23 \%)$, tetanus $(7 \%)$, congenital anomalies $(7 \%)$ and diarrhea $(3 \%){ }^{3}$ Error! Bookmark not defined.

The investigators personal experience reveals that in postnatal wards/areas nursing observations and care plans and their implementations are limited to the breast feeding and diet of mother but no one gives emphasis on full newborn care to prevent the neonatal mortality and morbidity rate. This study provides the baseline data about the care received by the newborns which will help postnatal mothers to gain awareness through various measures such as feedback sessions and in-service education programmes. However, research is an ongoing process and studies need to assess the consequences of lack of newborn care.

\subsection{Statement of Problem:}

A Quasi-experimental study to assess the effectiveness of an 'Instructional Teaching Programme' (ITP) on the Knowledge of Postnatal Mothers regarding Newborn Care in a selected Hospital, Dehradun, Uttarakhand, India, 2012

1.4 Objectives:

- To evaluate the effectiveness of an Instructional Teaching Programme regarding Newborn Care on the knowledge of postnatal mothers.

- To find association between the pretest knowledge score and selected socio-demographic variables of postnatal mothers.

\subsection{Hypothesis:}

$\mathbf{1 H}_{1}$-The mean post-test knowledge score would be significantly higher than mean pre-test knowledge score among postnatal mothers regarding newborn care at the level of $\mathrm{p}<0.05$.

$\mathbf{2} \mathbf{H}_{1}$ - The mean post-test knowledge score would be significantly higher than mean pre-test knowledge score according to four aspects among postnatal mothers regarding newborn care at the level of $\mathrm{p}<0.05$.

$\mathbf{3} \mathbf{H}_{1}$ - There would be significant association between of pre-test knowledge score of postnatal mothers regarding newborn care with their selected demographic variables at the level of $\mathrm{p}<0.05$.

\subsection{Conceptual Framework:}

A frame work serves as a spring board for scientific advancement. ${ }^{7}$ The conceptual framework selected for the study was based on Imogene Kings "Goal Attainment Model". The theory focus on interpersonal systems reflects Kings' belief that the practice of nursing is differentiated from that of other health care professionals by what nurses do with and for the individual. The major elements of the theory are seen in interpersonal system in which two people, who are usually strangers, come together in a health care organization to help and be helped to maintain the state of health that permits functioning in roles. The concepts of theory are perception, action, interaction and transaction. The concepts are interrelated in every nursing situation.

\section{METhODOLOGY}

The research design used in this study was Quasi-experimental in nature. The study was conducted at multi-specialty, teaching hospital in Uttarakhand, INDIA. The sample of 62 postnatal mothers was selected by using consecutive sampling technique. The tool used for the study was the structured knowledge questionnaire designed by the researcher consisting of section A (Socio- demographic variables such as age, educational status, occupation, parity and area of living and Section B (consisting of 45 items related to Knowledge regarding Newborn Care related to four aspects i.e. breast feeding, prevention of infection, immunization and prevention of low body temperature). The content validity of the tool was ensured by giving the tool to experts in the field of Nursing and Medical from Obstetrics and Gynecology, Child health and Neonatology. A pilot study was conducted on 6 postnatal mothers in the selected hospital. Reliability of tool was established by split half method following spearman brown formula. The reliability of tool was calculated and it was $r=0.93$. 


\section{III.}

RESULTS AND FINDINGS

3.1 Related to Socio-Demographic Profile of Postnatal Mothers:

Table No.1: Socio-Demographic Profile of the postnatal mothers

\begin{tabular}{|c|c|c|}
\hline Sample Characteristics & Frequency (f) & Percentage (\%) \\
\hline \multicolumn{3}{|l|}{ AGE IN YEARS } \\
\hline $18-25$ & 35 & 56 \\
\hline $26-33$ & 23 & 38 \\
\hline Above 33 & 04 & 06 \\
\hline \multicolumn{3}{|l|}{ EDUCATIONAL STATUS } \\
\hline No formal Education & 05 & 08 \\
\hline Primary Education & 05 & 08 \\
\hline Secondary Education & 09 & 15 \\
\hline Above Higher Secondary & 43 & 69 \\
\hline \multicolumn{3}{|l|}{ OCCUPATION } \\
\hline Home Maker & 54 & 87 \\
\hline Skilled Worker & 07 & 12 \\
\hline Unskilled Worker & 01 & 01 \\
\hline \multicolumn{3}{|l|}{ PARITY } \\
\hline Primipara & 34 & 54 \\
\hline Multipara & 21 & 35 \\
\hline Grand Multipara & 07 & 11 \\
\hline \multicolumn{3}{|l|}{ AREA OF LIVING } \\
\hline Urban Area & 36 & 58 \\
\hline Rural Area & 23 & 37 \\
\hline Town & 03 & 05 \\
\hline
\end{tabular}

The data shown in table no.1 depicts the percentage and frequency of characteristics which shows that most $35(56 \%)$ of postnatal mothers falls between the ages of 18 to 25 years; $23(38 \%)$ fell between the ages group between $26-33$ years and $4(6 \%)$ were found above 33 years.

Among the sample of 62, $43(69 \%)$ of postnatal mothers were above higher secondary education; 9 $(15 \%)$ were secondary educated and $5(8 \%)$ of postnatal mothers was had primary education or no formal education.

Regarding occupation majority of the mothers $54(87 \%)$ were homemakers, 7 (12\%) were skilled workers and only $1(1 \%)$ were unskilled worker. The parity of mothers were as follows; 34 (54\%) Primipara, 21 (35\%) Multipara and $7(11 \%)$ Grand Multipara. Regarding the area of living most of the mothers $36(58 \%)$ belonged to urban area, $23(37 \%)$ were from rural area and $3(5 \%)$ belonged to town.

From the socio- demographic data it could inferred that most of the mothers were from the age group of 18-25 years and majority of them were homemakers. Most of the mothers were having secondary educated and belonged to urban area.

\subsection{Comparing the knowledge of postnatal mothers according to grading at pre and post- test level:}

Data presented in figure no.1 depicts the grading of knowledge score at pretest and post-test level. In the pre-test majority of the postnatal mothers $(77.42 \%)$ had good level of knowledge, $14.52 \%$ mothers showed average level of knowledge and only $8.06 \%$ mothers had very good level of knowledge and $100 \%$ mothers got very good level of knowledge at post-test level.
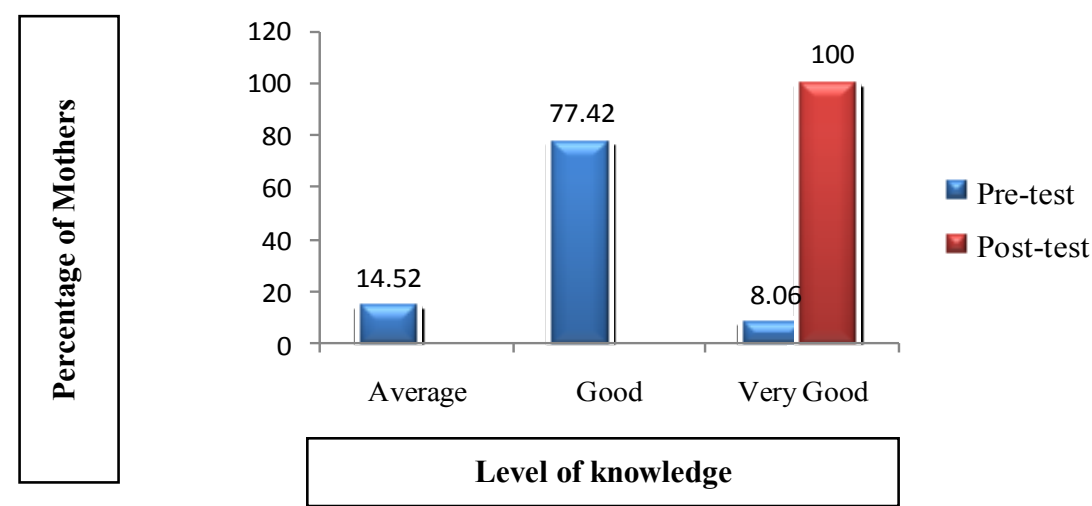

Figure No.1: Percentage distribution of the postnatal mothers according to Grading. 
3.3 Comparing knowledge score according to four aspects of newborn care among postnatal mothers

Table No. 2 Knowledge score according to four aspects of Newborn Care

\begin{tabular}{|c|c|c|c|c|c|}
\hline \multirow[t]{2}{*}{ Area of Knowledge } & \multicolumn{2}{|c|}{$\begin{array}{l}\text { Pre-Test } \\
\end{array}$} & \multicolumn{2}{|c|}{ Post-Test } & \multirow[b]{2}{*}{ 't' Value } \\
\hline & Mean \pm SD & $\begin{array}{c}\text { Mean } \\
\text { Percentage } \\
(\%)\end{array}$ & Mean \pm SD & $\begin{array}{c}\text { Mean } \\
\text { Percentage } \\
(\%)\end{array}$ & \\
\hline Breast feeding & $10.7 \pm 1.92$ & 71.33 & $14.4 \pm 0.58$ & 96 & $14.8^{*}$ \\
\hline $\begin{array}{l}\text { Prevention of } \\
\text { infection }\end{array}$ & $7.4 \pm 1.23$ & 74 & $9.3 \pm 0.70$ & 93 & $11.17^{*}$ \\
\hline Immunization & $6.5 \pm 1.86$ & 59 & $10.2 \pm 0.71$ & 92.72 & $15.41^{*}$ \\
\hline $\begin{array}{l}\text { Prevention of low } \\
\text { body temperature }\end{array}$ & $5.5 \pm 1.36$ & 61.77 & $8 \pm 0.78$ & 88.88 & $14.70^{*}$ \\
\hline
\end{tabular}

Table no. 2 reveals that the mean post-test knowledge score in all four aspects was apparently higher than their respective mean pre-test knowledge score. The mean percentage pre-test scores ranged between $59 \%$ to $74 \%$, whereas in post-test scores means ranged between $88.88 \%$ to $96 \%$. In pre-test the highest mean percentage score was in the area of prevention of infection (74\%) and lowest pre-test was in the area of immunization (59\%). The highest post-test mean percentage was in the area of breast feeding (96\%) and lowest score was in the area of prevention of low body temperature $(88.88 \%)$. The mean post-test knowledge score was higher than that of their pre-test knowledge score. Hence, paired t test was applied to find if the mean difference was statistically significant. From the above data, it could be inferred that in all areas the gain of knowledge was not by chance but it was as a result of intervention.

\subsection{Effectiveness of an instructional teaching programme regarding newborn care on the knowledge of postnatal mothers:}

Table No. 3: Pretest and post test knowledge score of postnatal mothers regarding newborn care

\begin{tabular}{|c|c|c|c|c|}
\hline Knowledge Scores & Range scores & Mean \pm SD & Mean difference & 't'value \\
\hline Pre-test & $21-38$ & $30 \pm 4.3$ & \multirow[b]{2}{*}{12} & \multirow[b]{2}{*}{$22.22 *$} \\
\hline Post-test & $39-45$ & $42 \pm 1.1$ & & \\
\hline
\end{tabular}

Table no. 3 shows that the mean of post-test knowledge score (42) of the postnatal mothers was higher than that of the mean of pre-test knowledge score (30). Hence the scores predicted that the significant difference between the mean of pre-test and post-test at $\mathrm{p}<0.05$ level. The research hypothesis $\left(\mathrm{H}_{1}\right)$ was accepted as the difference of mean observed was of significant difference and the 'Instructional Teaching Programme' was effective to upgrade knowledge of postnatal mothers.

\subsection{Association between socio-demographic variables with knowledge of the postnatal mothers at pre-test} level

Table No-4: Association between demographic variables with knowledge of postnatal mothers

\begin{tabular}{lccc}
\hline Variables & Below Median & $\begin{array}{c}\text { At and Above } \\
\text { Median }\end{array}$ & $\chi^{\mathbf{2} \text { cal value }}$ \\
\hline AGE IN YEARS & 41 & 15 & $\mathbf{5 . 5 5}^{*}$ \\
$\quad 20-30$ & 01 & 05 & \\
$\quad 31-40$ & 04 & 01 & 0.47 \\
EDUCATION & 38 & 19 & \\
No Formal Education & & & 2.41 \\
Educated & 39 & 15 & \\
OCCUPATION & 03 & 05 & 0.27 \\
Homemaker & & & \\
Working & 24 & 10 & 0.11 \\
PARITY & 18 & 10 & \\
Primipara & & & \\
Multipara & 25 & 11 & Significan \\
AREA OF LIVING & 17 & 09 & \\
Urban & & & \\
Rural & & & \\
\hline
\end{tabular}


Table no.4 shows that only age was having statistical significant association with the pre-test knowledge score at the level $\mathrm{p}<0.05$. Other Socio-Demographic variables like Education, Occupation, Parity and Area of living statistically not having any association with pre-test knowledge score at the level $\mathrm{p}<$ 0.05 .Hence, there was no evidence to reject null hypothesis for the variable age.

\section{NURSING IMPLICATIONS}

The health of a nation is the wealth of the nation. Today's children are tomorrow's adults. Among the life span of the childhood period, neonatal period is very crucial. The neonatal period determines to a large extent, the overall health status of the child and in turn adult life. Birth is a major challenge to the newborn to negotiate successfully from intrauterine to extra uterine life. A newborn baby is considered to be tiny and powerless, completely dependent on others for life.

The findings of the study have implications for Nursing Practice, Nursing Education, Nursing Administration and Nursing Research.

\section{Nursing Practice:}

- Several implications can be drawn from the present study for Nursing Practice. Instructional Teaching programme conducted by nursing personnel, both in hospital and community areas, helps to enhance the knowledge of postnatal mothers about newborn care and helps to reduce the neonatal mortality.

- The nurse plays an imperative role in disease prevention and health promotion. Education programmes with effective teaching strategies, motivate people to follow healthy practices in day-to-day life. The educative role of the nurse needs to be emphasized.

- Health information can be imparted through different methods like lecture cum discussion, real objects, mass media, pamphlets etc. Any teaching strategy which is simple, clear and attractive makes learners interested to follow instructions easily. Nurses have to position themselves in all areas of community health practices, so as to help people in leading healthy lifestyles by preventing health problems. Hence, nurses should take keen interest in preparing different teaching strategies suitable for the people.

\section{Nursing Education:}

- Since today's nursing students are tomorrow's staff nurses, educators, administrators and supervisors, this study has great implications in Nursing Education. Nursing teachers should emphasize the importance of health education and the methods of imparting education in an effective way during the training period of students.

\section{Nursing Administration:}

The nurse administrator needs to take interest in providing information on healthcare of newborn baby. The nurse, as an administrator, should plan and organize CNE (Continuing Nursing Education) programmes for the nursing personnel and motivate them in conducting instructional teaching programs regarding newborn care. Planning and organization of such programmes requires efficient team work, planning for man power, money, material, method and time to conduct successful instructional teaching programmes.

\section{Nursing Research:}

- Research provides nurses needs credibility to influence decision making, policy and protocol formulation regarding interventional strategies to meet the specific need for educating mothers of newborn babies regarding newborn care.

- Findings of the present study suggest that nurses in hospital and those working in the community need to encourage the mothers to read, and discuss about newborn care. An experimental research can be conducted to assess the knowledge, attitude and practice of postnatal mothers regarding newborn care.

\section{CONCLUSION}

Based on the findings of the study, it is concluded that most of the mothers had very good knowledge regarding Newborn Care after implementation of Instructional Teaching Programme.

The following conclusions were drawn on the basis of the present study

1. The findings showed that out of 62 postnatal mothers 48 had good level of knowledge in the pre-test knowledge score on the newborn care. The mean post-test percentage score and the gain scores in all areas were found to be significantly high, the maximum gain being in the area of breast feeding and lowest in the area of prevention of low body temperature. 
2. From the findings of the study, it can be concluded that the administered a teaching programme was effective as a method to improve the knowledge of postnatal mothers by saying that cognitive change can be brought about by teaching programme.

3. From the findings of the study, it can be concluded that the selected variables viz. education, occupation, parity and area of living have no significant association with the knowledge about newborn care but age of the mother had the significant association with knowledge.

\section{ACKNOWLEDGEMENT}

The essence of all beautiful art, all great art is gratitude! Gratitude can never be expressed in words, but this is only a deep perception which makes the words to flow from one's inner heart. The success of publishing this study would not have been possible without the help, guidance and contributions of Dr. Kathleen Mckeehan, Nursing Consultant and Dr. Sanchita Pugazhendi, Professor and Principal of Himalayan College of Nursing, Dehradun. We express our gratitude for the guidance provided by the Research Committee of HIHT.

\section{REFERENCES}

[1]. Anil Narang,Srinivas Mukri.Research in neonatology, Indian Pediatr2002;17:170

[2]. Kathmandu University Medical Journal (2009);7(3):231-7.[Internet document]cited on 2011 April 9.Available from:http://www.kumj.com.np/ftp/issue/27/231-237.pdf

[3]. U.K. Choudhry, Traditional practices of women from India: pregnancy, childbirth, and newborn care in North York Ontario Canada. (cited in April 2011).

[4]. G.L. Dhamstadt, V. Kumar, R. Yadav, Introduction of community based skin to skin care in rural Uttarpradesh, India, J Perinatol, 2006;26;597-604.

[5]. S. Menaka, Assess the effectiveness of structured teaching programme on newborn care among primigravida mothers in Bangalore. [internet document]cited $\quad$ on $2012 \quad$ April $\quad 20, \quad$ Available http://119.82.96.198:8080/jspui/bitstream/123456789/1412/1/CDNNOBG00018.pdf

[6]. World Health Organization, 1996 world health statistics annual Geneva: World Health Organization; 1998. A-5.

[7]. Polit F Denis and Cheryl tatano beck. Nursing research generating and assessing evidence for nursing practice. New Delhi Lippincott Williams and Wilkins; 8 th edition.

\section{OTHER REFERENCES}

[8]. Ministry of health his majesty's Government.Annual report (2004/05) Nepal:Department of health services.Ministry of Health;2006.p.17.

[9]. Dutta Parul.Pediatric Nursing.New Delhi. $2^{\text {nd }}$ edition.Jaypee;2009

[10]. Report to Congress, Health-Related Research and Development Activities at USAID An Update on the Five-Year Strategy. 20062010.(cited in April 2011).available from : http://pdf.usaid.gov/pdf docs/PDACL916.pdf

[11]. Wong and Whaley. Essentials of pediatric nursing. 3rd edition. Mosby Publisher; p. 182-3.

[12]. Mohamed Asif Padiyath, Vishnu Bhat B, Maheswari Ekambaram. Knowledge attitude and practice of neonatal care among postnatal mothers. Vol. 14(2) (2010-07 - 2010-12) (cited on 2011 March) available from: http://www.indmedica.com/journals.php?journalid=13\&issueid=145\&articleid=1960\&action=article.

[13]. Obimbo E, Musoke RN, Were F. Knowledge, attitudes and practices of mothers and knowledge of health workers regarding care of the newborn umbilical cord. East Atr Med J. 2011 Apr ; 76(8) :425-9.

[14]. Healmy, and Balggat. (2007), Newborn care giving by primipara and multipara mothers at home in tanta city, Journal of Egyptian Public Health Association, p. 311-6.

[15]. Lee H J, Kim M H. (2003). A study of prenatal knowledge and confidence in newborn care. Journal of Neonatal Care. P. $872-886$.

[16]. Fernando D, Senarath. (2003).Factors associated with maternal knowledge of newborn care among hospital delivered mothers in Srilanka, (cited in January 2012). Available http/www.journals.elsevierhealth.com/periodicals/trstmb/articles/P1130035920307000697/abstract

[17]. Osrin D, Tumbahangphe KM, Shrestha D, Mesko N, Shrestha BP, Manandhar MK. et al. Cross sectional, community based study of case of newborn infants in Nepal.BMJ.; 325(7372):1063.

[18]. Barnett S, Azad K, Barua S. Newborn care practices during childbirth and postnatal period: a comparison of three rural districts in Bangladesh. Health Popul Nutr. 2006 Dec; 24(4): 394-402.

[19]. Kamlesh Kumari Sharma, Smriti Arora, Lavanya Subhashini.To assess the knowledge, attitude and practice of parents and staff nurses regarding KMC in tertiary hospital New Delhi. $6^{\text {th }}$ International Nursing conference ICNN 2007.

[20]. Worku B, Kassie A. in 2002 on Kangaroo mother care. J Trop Pediatr. 2005 Apr;51(2):93-7.

[21]. Mullary LC, Katz J, Khatry SK, LeClerq SC, Darmstat GL, Tielsch JM. et al on Neonatal hypothermia .BMC Med. 2010 Jul 8;8:43.

[22]. Cramer K, Wiebe N, Hartling L, Crumley E, Vohra S. An occlusive skin wrap for premature neonates.(cited on jan 2012).

[23]. Iyengar SD, Bhakoo ON. On the traditional concepts and practices for the prevention of neonatal hypothermia .Epub,2010 Nov;126(5):p.1119-26.

[24]. Byaruhanga R, Okong P. (2005) The impact of newborn bathing on the prevalence of neonatal hypothermia in Uganda Acta Paediatrics.2005 Oct; 949(10):1462-7.

[25]. Sinha A, Yokoe D, Platt R.. in 2006.Epidemiology of neonatal infections .(cited in April 2011) available from: http://www.ncbi.nlm.nih.gov/pubmed/12634586Lippincott Williams \& Wilkins Ovid Technologies, Inc. Swets Information Services

[26]. Ladomenou F, Moschandreas J, Kafatos A, Tselentis Y, Galanakis E. on the effects of breastfeeding on the frequency and severity of infections (Cited in aril 2011) available from http://www.kumj.com.np/ftp/issue/27/231-237.pdf

[27]. Gagan Gurung. (2001). Practice on immediate care of newborn in the community of kailali district. (Cited in Jan 2012). Availa ble from http/www.nmcth.edu/nmcj_articles_pdf/volume_wise/nmcj_vol10_no1/ggurung.pdf

[28]. K Madhu, Sriram Chowdary, and Ramesh Masthi. Breast Feeding Practices and Newborn Care in Rural Areas .Indian J Community Med. 2009 July; 34(3): 243-246.

[29]. A Ayaz, S Saleem.the burden of neonatal mortality and prevalence of practices for newborn care. BMC Med. $2010 \mathrm{Jul}$ 8;8:43.

[30]. Shrestha M1, Singh R2, Upreti D3, Epidemiology of neonatal infections.(cited in april 2011). available from: http://www.ncbi.nlm.nih.gov/pubmed/12634586Lippincott Williams \& Wilkins Ovid Technologies, Inc. Swets Information Services 
[31]. Baqui Att, Williams EK, Darmstadt GL, Kumar V, Kiran TV, Panwar D et al. Newborn care in rural Uttar Pradesh: Indian J Pediatr. 2007 Mar; 74 (3) : 241-7.

[32]. Sreeramareddy CT, Joshi H.S, Srekumaran, Giris, Chuni N. Home delivery and newborn care practices among urban women in.2006 Aug 23; $6: 316-8$.

[33]. Rahi M, Taneja DK, Misra A, Mathur NB, Badhans. New born care practices in an urban slum of Delhi: Indian J Med Sci. 60 (12): 506-13.

[34]. Fikree FF, Ali TS, Durocher JM, Rahbar MH. Newborn care practices in low socio-economic settlements of Karachi, Pakistan: soc sci med.2005 mar; 60(5): 911-21.

[35]. Amy J Kesterton, John Cleland. Neonatal care in rural Karnataka: healthy and harmful practices, the potential for change.(cited in Jan 2012). Available from: http://www.biomedcentral.com/1471-2393/9/20

[36]. Elwyn Chomba, Elizabeth M, (2006), Effect of newborn care-training on neonatal mortality by education, (cited in Jan 2012). Available from: http/www.ncbi.nlm.nih.gov/pmc/articles.Dmc2592550

[37]. Binu V Sreekumaran. (2006). Newborn care practices among urban women in western Nepal. Journal of Pregnancy and Child Birth. p.6-7.

[38]. Muhammed Hussain Khan, Nargis Noman. (2000). Essential newborn care practice in hospital and home deliveries. (cited in Jan 2012). Available from: http/www.gjms786.com/files/GJMS\%20vol-4-1 (1).pdf

[39]. Wadde S.K, Vedpathak V.L, Yadav V.B. in Ambajogai. International Journal of Recent Trends in Science And Technology, EISSN 2249-8109, Vol.1( 3), 2011 p. 115-119, Statperson Publications, International Journal of Recent Trends in Science And Technology, E-ISSN 2249-8109, Volume 1, Issue 3, 2011 Breast Feeding Practices in Rural Mothers of Maharashtra. (Cited in Jan 2012). Available from: http://www.statperson.com/Journal/ScienceAndTechnology/HtmlBreast.php 